\title{
Intercontinental comparison of habitat levels of invasion between temperate North America and Europe
}

\author{
Veronika Kalusová, ${ }^{1,4}$ Milan Chytrý,,${ }^{1}$ Robert K. Peet, ${ }^{2}$ and Thomas R. Wentworth ${ }^{3}$ \\ ${ }^{1}$ Department of Botany and Zoology, Masaryk University, Kotlárská 2, 61137 Brno, Czech Republic \\ ${ }^{2}$ Department of Biology, University of North Carolina, Chapel Hill, North Carolina 27599-3280 USA \\ ${ }^{3}$ Department of Plant and Microbial Biology, North Carolina State University, Box 7612, Raleigh, North Carolina 27695-7612 USA
}

\begin{abstract}
Several studies have demonstrated that floras of the New World contain larger proportions of alien species than those of the Old World; however, the differences in fine-scale invasion patterns are poorly known. We compared the levels of invasion in analogous habitats of two environmentally similar regions in temperate North America and Europe (the Carolinas and the Czech Republic), using comprehensive vegetation-plot databases. Native and alien vascular plant species were identified within 4165 vegetation plots assigned to 12 habitats occurring in both areas. The level of invasion was calculated for each habitat (1) as the proportion of aliens recorded cumulatively across multiple plots (habitat scale) and (2) as the mean proportion of aliens per plot (plot scale), both separately for all alien species and for the subgroup of aliens originating in one region and invading the other. The proportions of species native on one continent and invading the other were also calculated for each habitat to compare the alien species exchange between continents. Habitat levels of invasion showed remarkably similar patterns on the two continents. There were significant positive relationships for the levels of invasion, both for all alien species (habitat-scale $R^{2}=0.907$; plot-scale $R^{2}=0.676$ ) and for those that originated on the opposite continent (habitat-scale $R^{2}$ $=0.624$; plot-scale $R^{2}=0.708$ ). In both regions, the most and the least invaded habitats were the same, but on average, North American habitats showed higher habitat-scale levels of invasion than their European counterparts. At the same time, a larger proportion of alien species was provided by European habitats for invasion to North America than vice versa. The consistent intercontinental pattern of habitat levels of invasion suggests that these levels are driven by similar mechanisms in distant regions. Habitat conditions are likely to have stronger effect on the level of invasion than the identity of alien species, as shown by similar levels of invasion in analogous habitats despite different geographical origins of alien species. The higher flux of alien species from Europe to North America is consistent with a generally higher level of invasion of North American habitats.
\end{abstract}

Key words: alien species; Czech Republic; habitats; level of invasion; North and South Carolina; plant communities; vascular plants.

\section{INTRODUCTION}

Invasion of alien plant species is among the major threats for ecosystems and native biota world-wide, causing substantial economic and ecologic losses $(\mathrm{Pi}-$ mentel et al. 2000, Vilà et al. 2011). Incidence of alien plants is unequal among regions, ecosystems, and habitats, and therefore describing and understanding observed invasion patterns is critical for development of reliable risk assessment schemes and effective management actions. However, studies providing quantitative comparisons of alien species occurrences in habitats are still scarce, differ in the type of input data and analytical methods, and are not easily comparable among regions. Early comparative studies investigated the outcome of invasion using expert assignments of alien plants from

Manuscript received 8 January 2015; revised 20 May 2015; accepted 2 June 2015. Corresponding Editor: G. A. Fox.

${ }^{4}$ E-mail: kalveron@tiscali.cz regional species lists to particular habitats occurring in the target regions (e.g., Crawley 1987). Numbers of alien species occurring in large regions were also compared between continents to assess the magnitude of invasion in the Old and New World (Di Castri 1989). These studies revealed notable differences in the numbers of alien species, but they concerned entire floras or regional species pools of individual habitats (e.g., Sádlo et al. 2007) rather than actual presence of alien species in local vegetation of individual sites.

Further studies compared the magnitude of invasion in small regions among different geographical areas. Lonsdale (1999) compiled data from different regions of the world and made important generalizations of largescale invasion patterns. He found that higher levels of invasion are in the temperate zone (as opposed to the tropics), on islands (as opposed to mainland areas), and in the New World (as opposed to the Old World). Recent comparative assessments focused on alien plants at the scale of particular habitats and sites as a 
convenient unit for invasion study and mapping (Chytrý et al. 2008a, Kalusová et al. 2014). Typically, the levels of invasion have been calculated as the mean number of alien species or proportion of alien to all species in a given habitat (Catford et al. 2012). However, such studies are so far strongly geographically biased, and they differ in the size of sampling units from which the data on the level of invasion are obtained. The most extensive multi-habitat studies using levels of invasion have been conducted in Europe across biogeographical regions (Chytrý et al. 2008b), at the national scale (Chytrý et al. 2005, Rejmánek et al. 2005, Maskell et al. 2006a, Vilà et al. 2007, Sîrbu et al. 2012, Medvecká et al. 2014), and in smaller areas (e.g., Kowarik 1995, PlantyTabacchi et al. 1996, Maskell et al. 2006b, Campos et al. 2013). Outside Europe, habitat levels of invasion have been explored to a lesser extent: multi-habitat studies were conducted in some parts and specific landscapes of the United States (e.g., Stohlgren et al. 1999, 2005, Brown and Peet 2003, Kelly et al. 2009) and in New Zealand (Wiser et al. 2011). Levels of invasion have shown substantial variation among habitats in all the studied regions, but a consistent pattern was found in a comparison of different regions (Chytrý et al. 2008b, Kalusová et al. 2014). The most and the least invaded habitats remained the same, despite their location in geographically distant regions (Pyšek and Chytrý 2014).

Although these studies described the variation in the levels of invasion among habitats in different regions and on different continents, a direct comparison of levels of invasion between corresponding habitats on different continents has never been done. Moreover, intercontinental patterns of plant invasion can be influenced by differences in size and composition of alien floras invading different continents, because groups of alien species from particular world regions may tend to occupy different habitats in their shared invaded range (Fridley 2008, Kalusová et al. 2013). Intercontinental patterns of habitat level of invasion by aliens with respect to their geographical origin have not yet been tested with fine-scale data.

Here we focus on intercontinental differences in actual levels of invasion between analogous habitats of the temperate zones of North America and Europe. Over several decades large numbers of vegetation-plot records have been gathered in different regions and habitats. We use two of the most comprehensive vegetation-plot databases available, one for eastern North America and one for central Europe, to calculate and compare the levels of habitat invasion in both regions.

Our aims are (1) to explore whether the levels of invasion across habitats are similar on both continents, despite different origin of alien species and different scales of resolution (data aggregated for a habitat, i.e., habitat scale; or individual vegetation plots within a habitat, i.e., plot scale), (2) to identify which habitats have the highest and lowest levels of invasion in North America and Europe, (3) to test whether the habitat level of invasion is higher in the New World (eastern North American) habitats than in their counterparts in the Old World (central Europe), and (4) to compare whether the flux of alien species is stronger from North American to European habitats or vice versa.

\section{Methods}

\section{Source databases and habitat delimitation}

This study is based on two comprehensive vegetationplot databases available for the two regions: the Carolina Vegetation Survey Database (CVSD; Peet et al. 2012) as a representative of eastern North American habitats and the Czech National Phytosociological Database (CNPD; Chytrý and Rafajová 2003) as a representative of European habitats. Both databases comprise records of species composition in vegetation plots that are assigned to units of the regional systems of vegetation classification. To obtain a list of consistently defined habitats shared by both regions, we merged classification units used in each database according to their ecological and floristic characteristics into broadly defined habitats (see Appendix A). Of these, we identified 12 analogous habitats occurring in both regions. Subsequently, we assigned vegetation plots to these broadly defined habitats, using the information on their assignment to finely defined units.

To avoid possible effects of different plot sizes, we used only plots of $100 \mathrm{~m}^{2}$ from forests and $10 \mathrm{~m}^{2}$ from non-forest habitats. These two different sizes were chosen because, in CNPD, most plots in non-forest vegetation are smaller than $100 \mathrm{~m}^{2}$, whereas vegetation plots in forests are often larger, following the tradition of European phytosociology (Chytrý and Otýpková 2003). CVSD contains nested-plot data sampled following a standard protocol (Peet et al. 1998, 2012), from which we randomly selected one subplot for each site of $100 \mathrm{~m}^{2}$ for forests and $10 \mathrm{~m}^{2}$ for non-forests. Plots of the same size were also selected from CNPD to obtain a comparable data set. In total, 1891 vegetation plots from the CVSD and 2274 vegetation plots from the CNPD were selected (for numbers of plots per each of analogous habitats see Kalusová et al. 2014). These subsets of CVSD and CNPD plots are hereafter called the North American data set and the European data set, respectively.

\section{Native and alien species identification}

Of the species records in vegetation plots, we considered only vascular plants. Subspecies and varieties were merged to the species level. Species difficult to identify were merged into aggregates or species sensu lato (see Appendix B). All taxa are hereafter referred to as species. For identification of native/alien status of species we combined the list of the Czech flora (Kubát et al. 2002), alien species list for the Czech Republic (Pyšek et al. 2002; species labeled as neophytes) and the PLANTS database, including species native/alien status 


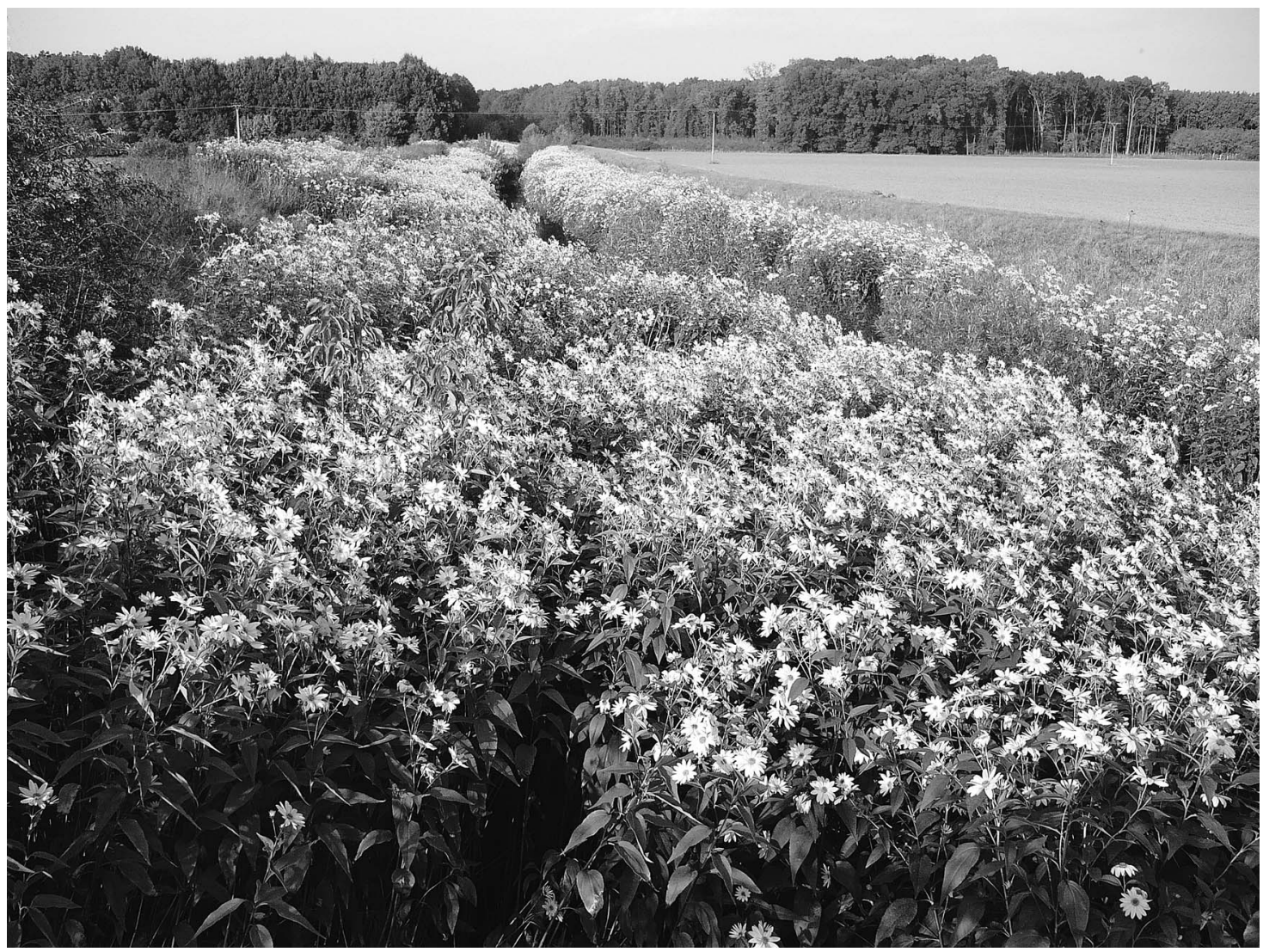

Plate 1. An example of alien plant invasion in the studied habitat, Jerusalem artichoke (Helianthus tuberosus L.) native to North America and introduced to the European continent, invades herb-dominated fringes along stream banks in the Czech Republic. Photo credit: V. Kalusová.

for North and South Carolina (data available online). ${ }^{5}$ Using these species lists, we identified eight classes of species contained in vegetation plots: (1) alien species in the European data set coming from North America; (2) alien species in the North American data set coming from Europe; (3) native species in the European data set invading North America; (4) native species in the North American data set invading Europe; (5) all native species in the North American data set; (6) all native species in the European data set; (7) all alien species in the North American data set, regardless of their native region; and (8) all alien species in the European data set, regardless of their native region. Aggregates or sensu lato species comprising both alien and native species and species with both alien and native populations on the same continent (19 species, e.g., Festuca rubra L., Rubus idaeus L.) were excluded. The alien species of all kinds are listed in Appendix B, cumulative numbers of alien of all kinds and native species identified in each habitat can be found in Appendix C.

\footnotetext{
${ }^{5}$ http://plants.usda.gov
}

\section{Data analysis}

We searched for differences in habitat levels of invasion between the studied regions of the two continents, assessing all alien species in the studied habitats regardless of their various geographical origins. Subsequently, we distinguished species having their native range in the opposite region to see whether the pattern of habitat invasion remains the same for this species subgroup (see Plate 1). The second step also enabled us to test whether there are generally higher invasion rates in the New World (eastern North America) compared to the Old World (central Europe), a pattern assumed in previous studies at the scale of particular habitats (Pyšek and Chytrý 2014), but never convincingly demonstrated.

The way of calculation of the habitat levels of invasion can affect the results, but it is not unified among studies. Therefore we used two approaches: habitat-scale calculation using vegetation-plot data aggregated within habitats and finer plot-scale calculation based on individual vegetation plots. In both approaches, we calculated the levels of invasion in North American and European habitats using species 
records in subsets of vegetation plots assigned to each habitat.

Because of different numbers of plots assigned to particular habitats, we calculated the habitat-scale level of invasion using sample-based rarefaction (Colwell et al. 2004) to estimate the numbers of species of all classes (1-8) and total number of species in each habitat. Rarefaction was run using the JUICE 6.3 program (Tichý 2002). It yielded the numbers of species found in a standardized number of 23 plots per habitat (the minimum number of plots available from any habitat), as a mean from 100 randomized subsets. Therefore, compared to previous studies (Crawley 1987), rather than estimating regional species pools for particular habitats, we calculated habitat levels of invasion based on an actual presence of alien species recorded in the plots and standardized for the same sample size.

The number of species calculated per habitat can also be affected by different plot sizes for forests and nonforest habitats $\left(100 \mathrm{~m}^{2}\right.$ and $10 \mathrm{~m}^{2}$, respectively). Thus, for the comparison of habitat levels of invasion, we did not use absolute species numbers but rather proportions of alien species, i.e., the number of alien species divided by the number of all species per given habitat, both calculated by rarefaction. Levels of invasion of North American and European habitats were calculated separately for all alien species, regardless of their native region (species classes 7 and 8) and for a subset of alien species originating in the other region (species classes 1 and 2). In habitat-level comparisons, all levels of invasion were expressed as the proportions of alien species to all species found in a habitat. To compare exchange rates of alien species from North American to European habitats and vice versa at the habitat scale, we calculated the proportion of native species per habitat invading the other region (species classes 3 and 4) to the number of all native species found in a habitat.

To compare habitat levels of invasion between both regions at the plot scale, we calculated the proportion of alien species to all species recorded in each vegetation plot using the JUICE 6.3 program (Tichý 2002), separately for aliens regardless of their native region (species classes 7 and 8) and aliens originating on the opposite continent (species classes 1 and 2), and averaged the proportions from plots within a habitat. To compare exchange rates of alien species from North American to European habitats and vice versa at the plot scale, we also calculated the proportion of native species per habitat invading the other region (species classes 3 and 4) to the number of all native species in each vegetation plot and averaged the proportions across plots of the same habitat.

To assess whether the pattern of habitat level of invasion (how much the habitat is invaded) is similar across the analogous habitats between the two geographic regions, we regressed habitat levels of invasion, calculated both at the habitat scale and at the plot scale, between analogous North American and European habitats. We performed two separate regression analyses for each scale. First, we calculated the habitat levels of invasion for all alien species regardless of their native range to explore whether particular habitats are invaded in both regions to a similar extent disregarding the origin of alien species. Second, we considered only the alien species with native range in the other region to assess the pattern for the subset of aliens exchanging between these two regions. We used major axis regression (MAR, model II linear regression; Legendre and Legendre 2012), which is appropriate when a predictor is not a fixed variable and thus can contain a measurement error. The significance of the slope was tested using 4999 permutations.

Further, we used $t$ tests to compare the differences in habitat levels of invasion for all alien species regardless of native origin and for aliens with native range in the other region between analogous habitats in North America and Europe. We also applied this test to a comparison of the proportions of North American native species invading European habitats and vice versa to establish which direction of invasion is stronger in particular habitats. These analyses were done for both habitat-scale and plot-scale data. Proportions at the habitat scale were square-root transformed and at the plot scale were arcsine square-root transformed to improve normality of the data. All analyses were performed using Statistica 9.1 (Statsoft 2010).

\section{Results}

The North American and European data sets together contained 428 alien species, of which 185 were alien only to North and South Carolina, 131 were alien only to the Czech Republic, and 112 species were alien to both regions. We identified 85 species native to the Carolinas and invading the Czech Republic and 156 species native to the Czech Republic and invading the Carolinas. Thus, $35 \%$ of alien species detected in the plots in the Czech Republic are native in the Carolinas, but $52 \%$ of alien species in the Carolinas plots are native in the Czech Republic.

There was a strong positive relationship between the habitat levels of invasion, both at the habitat scale (i.e., between proportions of all alien species found cumulatively in a set of vegetation plots of the analogous habitats in North America and Europe; $R^{2}=0.907 ; P<$ 0.001; Fig. 1a), and at the plot scale (i.e., between mean proportions of all aliens found in individual vegetation plots of the given analogous habitat; $R^{2}=0.676 ; P=$ 0.001 ; Fig. 1c). This indicates a similar pattern of habitat invasion on both continents. Individual habitats contained either relatively low, or intermediate, or relatively high proportions of alien species consistently on both continents, in spite of substantial differences in their native and alien floras. A positive relationship was also 
found when only alien species exchanging between the two regions on different continents were taken into account, both in the habitat-scale analysis $\left(R^{2}=0.624 ; P\right.$ $=0.001$; Fig. $1 \mathrm{~b})$ and in the plot-scale analysis $\left(R^{2}=\right.$ $0.708 ; P=0.001 ;$ Fig. $1 d)$. This indicates that the habitat levels of invasion are independent of the identity of alien species and their region of origin.

At the habitat scale, the highest proportions of alien species were found in nutrient-rich and frequently disturbed riparian habitats, including herb-dominated river fringes, alluvial forests and riverine scrub, and freshwater marshes (Table 1). In contrast, the least invaded habitats were those in stressed environments, especially those habitats on nutrient-poor soils, such as bogs and poor fens, bog and waterlogged coniferous woodlands, and mesic coniferous forests.

A similar pattern was found when proportions of alien species in individual plots within analogous habitats were compared (alien species regardless native region, Fig. 2a; alien species originating on the opposite continent, Fig. 2b). The similarity is also indicated by a positive correlation between habitat levels of invasion based on habitat-scale proportions and plot-scale mean proportions calculated for all alien species $(r=0.815, P$ $<0.001$ in North American habitats; $r=0.884, P=$ 0.015 in European habitats) and for exchanging aliens ( $r$ $=0.939, P<0.001$ in North American habitats; $r=0$. 817, $P=0.001$ in European habitats). Across all habitats, generally higher proportions of aliens per habitat at the habitat scale were found in North America (Fig. 3), both when considering all aliens $(t=2.320 ; P=$ $0.041)$ and only the subgroup of aliens exchanging between North America and Europe $(t=2.242 ; P=$ 0.047). At the plot scale, significant difference was confirmed for exchanging alien species $(t=2.910 ; P=$ 0.016). A majority of studied habitats at the habitat scale were either more invaded in North America or showed similar levels of invasion compared to their European counterparts, considering all alien species regardless of their origin (Fig. 1a). Considering only aliens of North American/European origin (Fig. 1b), the observed difference in the habitat levels of invasion between continents was higher than the difference based on all alien species. The only exceptions at the habitat scale showing higher levels of invasion in Europe than in North America were xeric to subxeric deciduous forests for all alien species and freshwater marshes for exchanging aliens. At the plot-scale, the comparison (Fig. 2a, b) revealed significant differences for alluvial forests and grasslands for both all and exchanging aliens and for mesic broad-leaved deciduous forests for exchanging aliens. Plots of all of these habitats were more invaded in North America than in Europe. In contrast, plots of freshwater marshes (for all and exchanging alien species) and xeric and subxeric broad-leaved forests (for all aliens) were more invaded in Europe.
Although there is some inconsistency in the level of invasion at the plot-scale between the analogous habitats of the two regions, habitat-level analysis revealed that temperate North American habitats are, on average, more invaded by aliens than European habitats, and this holds true both when considering all aliens and when considering only the species of European/North American origin. North American habitats also donate on average lower proportions of their native species for invasions to Europe than vice versa at the habitat scale (Fig. 4, $t=-9.298 ; P<0.001$ ) and also at the plot scale $(t=-7.332 ; P<0.001)$.

\section{DisCUSSION}

\section{Consistent patterns of the levels of invasion across habitats and between continents}

This study is the first directly comparing differences in the habitat levels of invasion between regions on different continents based on representative samples of vegetation plots assigned to particular habitats. The pattern of invasion by alien species was shown to be consistent between analogous habitats of temperate North America and Europe, regardless of whether all aliens or only exchanging species were taken into account. An equivalent pattern appeared when the level of invasion was measured as the proportion of aliens in a cumulative list of several plots from the habitat and when it was measured as a mean proportion of aliens in plots. Habitats most invaded in the North American data set were also most invaded in the European data set and, conversely, those with the lowest proportions of alien species in the North American data set were among the least invaded habitats within the European data set. Thus, we extend the validity of the results previously obtained by Chytrý et al. (2008b) for comparisons across three contrasting regions in Europe to an intercontinental scale and those of Kalusová et al. (2014) comparing the likelihood that a habitat will be a source of invasive species to the likelihood of its being invaded by species from the same habitat elsewhere.

Riparian habitats were among the most invaded habitats, both in the current intercontinental and previous European study, whereas bogs and poor fens were among the least invaded in both cases. The robustness of this pattern was supported by the fact that the same pattern was observed for all aliens as well as subsets of aliens restricted to a particular native range. Therefore, different geographical origin of alien species seems to have negligible effect on the differences in habitat levels of invasion within continents. We did not consider the most invaded habitats, which in both Europe and North America are human made, such as ruderal sites and arable land, because such data were not available in CVSD. However, based on our field experience we have no reason to think the results would have been any different. Natural habitats with the highest proportions of alien species, including herb- 


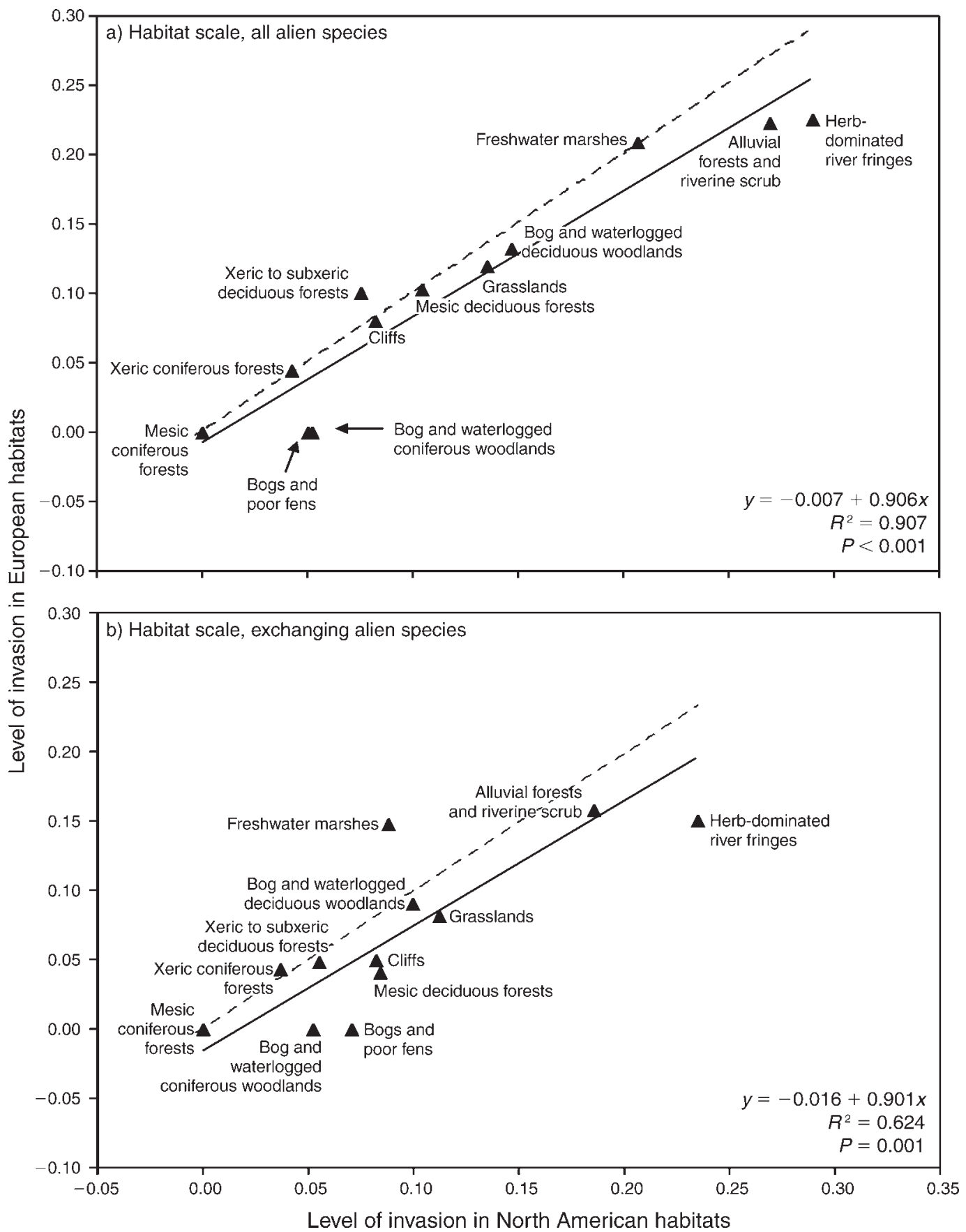

FIG. 1. The relationship between habitat levels of invasion in North American and European habitats, assessed at (a, b) the habitat scale (proportion of alien among all species in cumulative species lists for each habitat) and (c, d) the plot scale (mean of proportions of alien species across all plots of a habitat) and $(a, c)$ considering all alien species regardless of their native range and $(b, d)$ only the alien species that are native to the opposite region. The dashed line in each panel indicates unit slope; habitat position on this line indicates that the habitat levels of invasion in Europe and North America are equal; habitats occurring above it are more invaded in Europe, and those below it are more invaded in North America. The solid line is the regression line.

dominated river fringes, alluvial forests and riverine scrub, and freshwater marshes, have several attributes in common. They are strongly influenced by both human activities and water dynamics, and they are not only nutrient-rich but also receive external nutrient input via flood sediments (Planty-Tabacchi et al. 2001, Richardson et al. 2007, Kalusová et al. 2014). In contrast, the least invaded habitats in our study (mires and coniferous forests) are characterized by low and infrequent disturbance, nutrient-poor soils, and occurrence in 


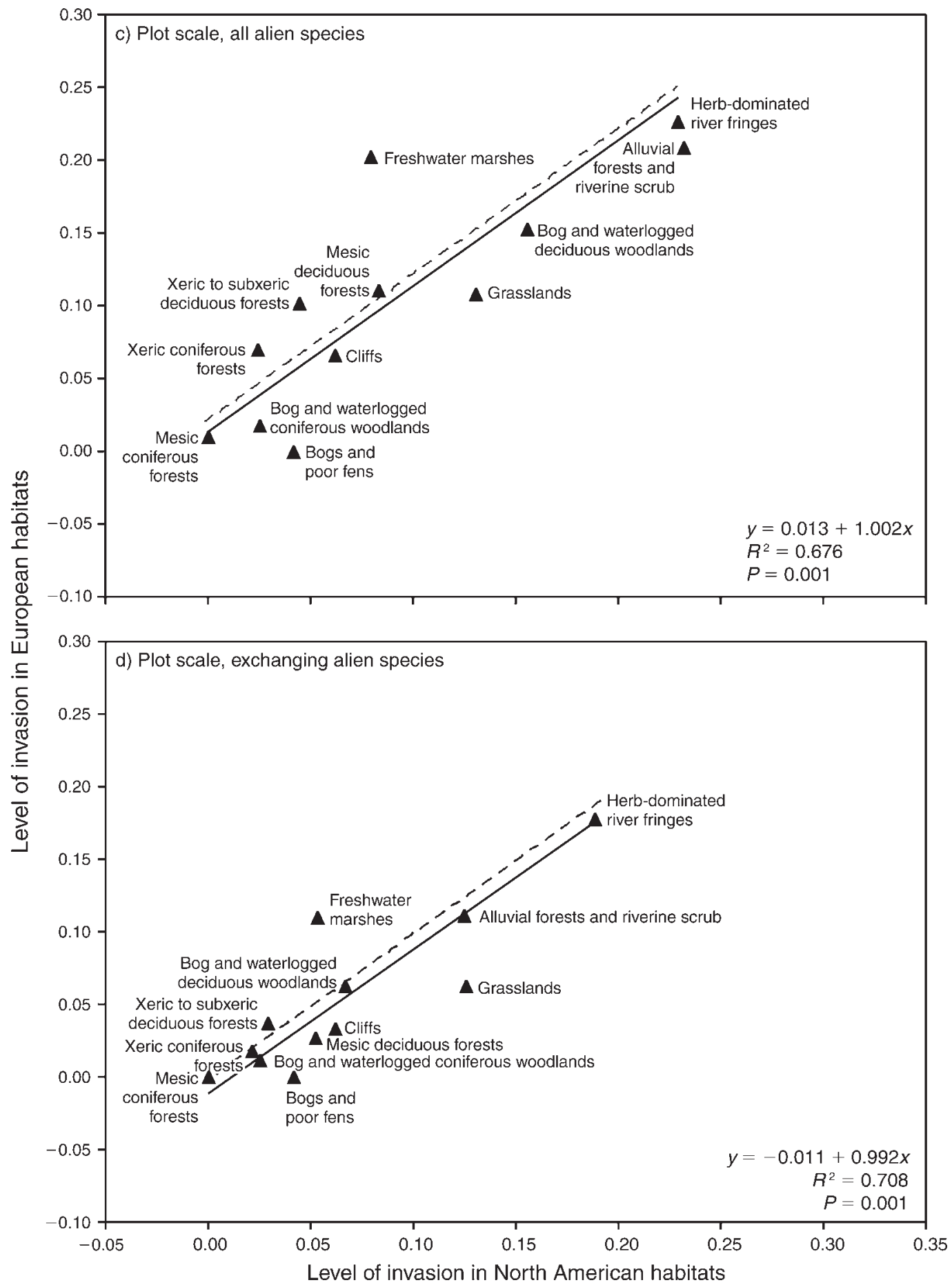

FIG. 1. Continued.

sparsely populated areas. Such attributes are in accordance with the fluctuating resource availability hypothesis (Davis et al. 2000), which proposes that habitats susceptible to invasion are those with high fluctuations of limiting resources (e.g., nutrient content) or frequent disturbances followed by nutrient release that is available for newcomers. In contrast, habitats resistant to invasion are little disturbed and have stable, often low, levels of limiting resources (Alpert et al. 2000). A similar pattern was reported from New Zealand forests and shrublands (Wiser et al. 2011), where the recently disturbed habitats at lower elevations were the most 
TABLE 1. Habitats represented in both the North American (NA) and European (EU) data sets: (a) the number of all alien species per habitat divided by the number of all species per habitat; (b) the number of species alien to NA with a native range in EU or vice versa per habitat divided by the number of all species per habitat; (c) the number of species native to NA and alien to EU or vice versa divided by the number of all native species per habitat.

\begin{tabular}{|c|c|c|c|c|c|c|}
\hline \multirow{2}{*}{ Analogous habitats $\dagger$} & \multicolumn{2}{|c|}{$\begin{array}{l}\text { (a) Proportion of } \\
\text { aliens regardless } \\
\text { of their origin }\end{array}$} & \multicolumn{2}{|c|}{$\begin{array}{l}\text { (b) Proportion of } \\
\text { aliens exchanging } \\
\text { between the two regions }\end{array}$} & \multicolumn{2}{|c|}{$\begin{array}{l}\text { (c) Proportion of } \\
\text { native species invading } \\
\text { the other region }\end{array}$} \\
\hline & NA & EU & NA & EU & NA & EU \\
\hline Herb-dominated river fringes & 0.084 & 0.050 & 0.055 & 0.023 & 0.083 & 0.252 \\
\hline Freshwater marshes & 0.043 & 0.044 & 0.008 & 0.022 & 0.021 & 0.198 \\
\hline Bogs and poor fens & 0.005 & 0 & 0.003 & 0 & 0.010 & 0.045 \\
\hline Grasslands & 0.018 & 0.014 & 0.013 & 0.007 & 0.022 & 0.241 \\
\hline Cliffs & 0.007 & 0.006 & 0.007 & 0.002 & 0.042 & 0.187 \\
\hline Alluvial forests and riverine scrub & 0.073 & 0.050 & 0.035 & 0.025 & 0.094 & 0.220 \\
\hline Bog and waterlogged coniferous woodlands & 0.003 & 0 & 0.003 & 0 & 0.011 & 0.069 \\
\hline Bog and waterlogged deciduous woodlands & 0.022 & 0.018 & 0.010 & 0.008 & 0.045 & 0.183 \\
\hline Mesic coniferous forests & 0 & 0 & 0 & 0 & 0.036 & 0.095 \\
\hline Mesic broad-leaved deciduous forests & 0.011 & 0.010 & 0.007 & 0.002 & 0.063 & 0.165 \\
\hline Xeric coniferous forests & 0.002 & 0.002 & 0.001 & 0.002 & 0.012 & 0.201 \\
\hline Xeric to subxeric deciduous forests & 0.006 & 0.010 & 0.003 & 0.002 & 0.053 & 0.180 \\
\hline
\end{tabular}

Note: Numbers of species of all kinds were obtained via rarefaction from a sample of vegetation plots assigned to each habitat. $\uparrow$ Common to NA and EU data sets.

invaded, and the undisturbed habitats in montane areas were the least disturbed.

Habitat level of invasion is influenced not only by inherent properties influencing invasibility, but also by propagule pressure (Lonsdale 1999), though this effect is difficult to measure and is usually estimated via surrogate variables such as human population density, land use (Chytrý et al. 2008a), proximity to moving water (Brown and Peet 2003), or trade intensity (Thuiller et al. 2005). Another factor influencing habitat invasions is the alien species pool (Kalusová et al. 2014). Riparian habitats were previously shown to have a large a) All alien species

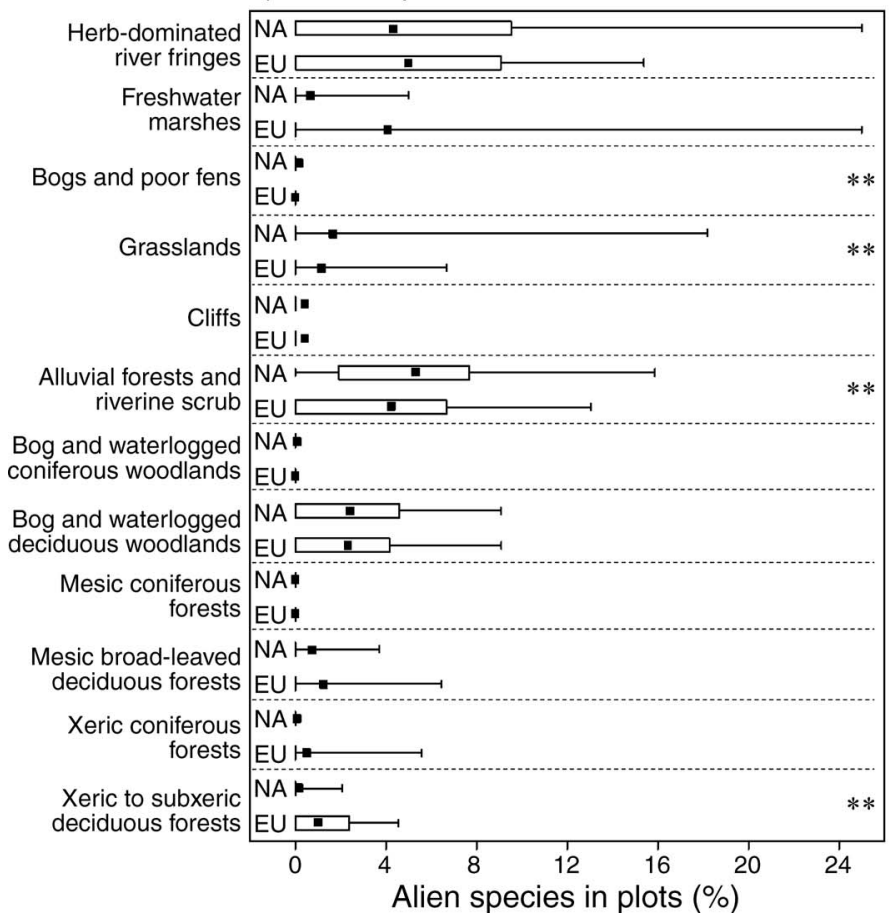

b) Alien species originating in opposite continent

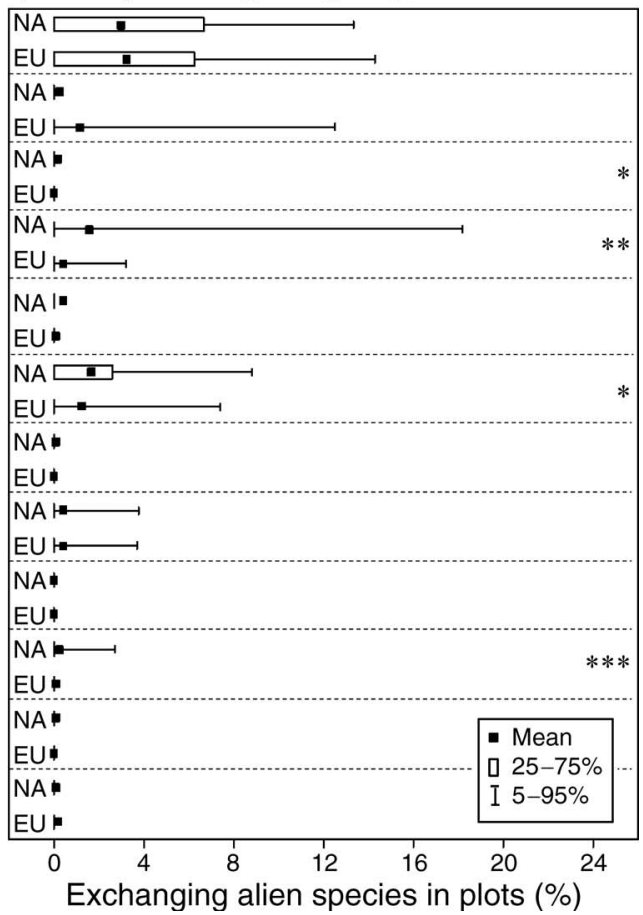

FIG. 2. Percentages of (a) all alien species regardless of their origin and (b) alien species originating in the opposite continent in plots assigned to analogous habitats in North America (NA) and Europe (EU) (plot-scale data). The significance of the differences in the means of alien proportions in plots assigned to the analogous habitats were tested using $t$ tests for independent samples.

* $P<0.05 ; * * P<0.01 ; * * * P<0.001$. 


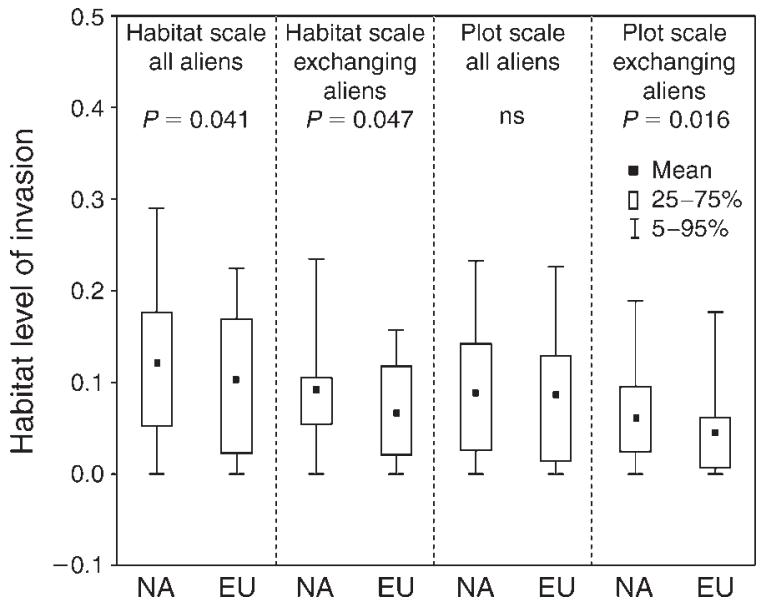

FIG. 3. Comparison of the levels of invasion across all habitats in North America and Europe, considering all alien species regardless of their native range and only the alien species exchanging between the regions. Levels of invasions were calculated at the habitat-scale as the mean proportion of alien species in cumulative species list of a habitat and at the plotscale as the mean proportion of alien species across plots of a habitat. Differences were tested using $t$ tests for dependent samples; ns, nonsignificant.

global pool of alien species able to establish there, whereas habitats in more extreme conditions, such as mires and coniferous woodlands, have a low species pool of ecologically compatible aliens (Brown and Peet 2003, Kalusová et al. 2013). The proportions of alien species adapted to specific habitats among all incoming alien species can affect the level of habitat invasion worldwide.

From a theoretical perspective, the consistency of habitat invasion patterns among regions supports the notion that the outcome of habitat invasion is determined by the same general mechanisms everywhere in spite of the differences in species composition of native and alien floras or in socioeconomic, climatic, and biogeographical characteristics of the regions. This finding was made at the regional scale in Europe (Chytrý et al. 2008b), and we extend its validity to the intercontinental scale. This knowledge can be incorporated into risk assessment schemes and used for setting priorities for monitoring and management of alien species. However, previous comparative studies across broader ranges of habitats have all been from temperate regions, which are the most explored with respect to both habitat classification and invasion patterns (Pyšek et al. 2008, Pyšek and Chytrý 2014). Studies from other biomes are needed to obtain a more complete picture.

\section{Intercontinental differences in the magnitudes of the habitat invasion}

Our study provided a rigorous test of the differences in the overall extent of invasion between the New World and the Old World at the scale of habitats. The notion of the higher magnitude of invasion in New World habitats was based on the comparison of New World and Old World alien floras (di Castri 1989, Richardson and Rejmánek 2011) and comparisons of regional species lists, without considering potential differences between habitats (Lonsdale 1999). So far only Pyšek et al. (2010) informally compared the habitat-scale data published in separate studies from North America (Stohlgren et al. 1999, 2005) and Europe (Chytrý et al. 2008b), suggesting that some North American natural habitats are invaded more than the most invaded European human-made habitats. Our study, based on comparable data and analogous habitats, showed that North American habitats contain, on average, higher proportions of aliens than the analogous European habitats. Several explanations for higher levels of invasion in North America have been proposed. Di Castri (1989) assumed that species evolved in European habitats, influenced by humans for a long time, are able to spread rapidly across relatively recently human-disturbed habitats in the New World. However, this pattern has been so far documented only for grasslands (Seastedt and Pyšek 2011, Hejda et al. 2015). Also, a higher rate of alien introduction from the Old to the New World following European colonization (Lonsdale 1999) could have played a role, as was supported by our analysis at both resolution scales, which revealed unequal exchange of alien species between the studied regions in eastern North America and Europe. European habitats provided more alien species to North America than did their North American counterparts to Europe. Another explanation suggests that species inhabiting larger land masses are better invaders due to their evolution in more diverse and thus more competitive environments and,

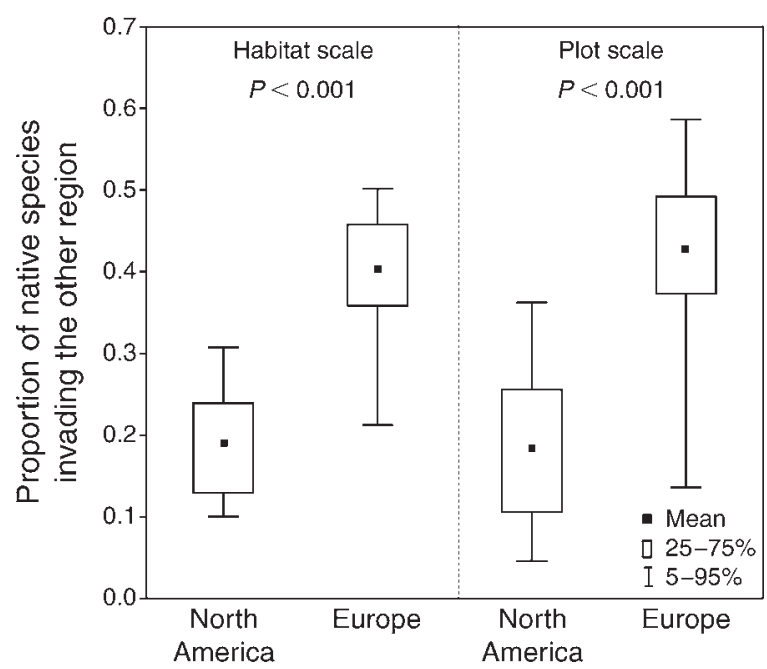

FIG. 4. Comparison of mean proportions of native species in North American habitats invading European habitats and vice versa. The habitat-scale (i.e., the proportion of native invading species in a cumulative species list of each habitat) and plot-scale (i.e., the proportion of native invading species averaged across plots assigned to a habitat) differences were tested using $t$ tests for dependent samples. 
therefore, better able to replace species evolved in smaller regions (Darwin 1859, Darlington 1965, Fridley and Sax 2014).

However, not all habitats showed higher level of invasion in North America at both the habitat and the plot scales. Hejda et al. (2015) found that grasslands of the Old World provided disproportionately many invasive species to the New World, whereas wetlands of the New World provided disproportionately many invaders to the Old World. This is also visible in our results, both at the habitat and the plot scale, where freshwater marshes are shown to experience higher level of invasion in Europe than in North America, whereas grasslands appear to be more invaded in North America.

Fridley (2008) found in eastern North America a higher proportion of aliens from northern and central Europe as well as the Mediterranean region (39\%) than of aliens from Asia (29\%). In the Czech Republic more aliens (neophytes) came from the Mediterranean region (28.7\%) and other parts of Europe (19.9\%) than from North America (Pyšek et al. 2012). This could influence the observed differences in levels of invasion between North American and European habitats. These differences are lower if based on all alien species than if only North American/European alien species are taken into account, because there are generally more European species invading eastern North America than North American species invading Europe. With all aliens taken into account, the levels of invasion in Europe are increased by aliens originating in the other parts of the European continent.

The increasing availability of data sets covering a broad spectrum of habitats in various parts of the World (Dengler et al. 2012) suggests a promising avenue for future research. Such research would likely include testing the differences in habitat levels of invasion and the influence of bias in exchange of alien species (alien species pools) between other continents, all of which can contribute to our broad understanding of large-scale patterns of habitat invasion.

\section{ACKNOWLEDGMENTS}

This research was funded by the Czech Science Foundation (project no. 14-36079G, Centre of Excellence PLADIAS), Masaryk University (MUNI/A/0757/2012), and the North Carolina Ecosystem Enhancement Program.

\section{Literature Cited}

Alpert, P., E. Bone, and C. Holzapfel. 2000. Invasiveness, invasibility and the role of environmental stress in the spread of non-native plants. Perspectives in Plant Ecology, Evolution and Systematics 3:52-66.

Brown, R. L., and R. K. Peet. 2003. Diversity and invasibility of southern Appalachian plant communities. Ecology 84:3239.

Campos, J., I. Biurrun, I. García-Mijangos, J. Loidi, and M. Herrera. 2013. Assessing the level of plant invasion: A multiscale approach based on vegetation plots. Plant Biosystems 147:1148-1162.
Catford, J., P. Vesk, D. M. Richardson, and P. Pyšek. 2012. Quantifying levels of biological invasion: towards the objective classification of invaded and invasible ecosystems. Global Change Biology 18:44-62.

Chytrý, M., V. Jarošík, P. Pyšek, O. Hájek, I. Knollová, L. Tichý, and J. Danihelka. 2008a. Separating habitat invasibility by alien plants from the actual level of invasion. Ecology 89:1541-1553.

Chytrý, M., L. C. Maskell, J. Pino, P. Pyšek, M. Vilà, X. Font, and S. M. Smart. 2008b. Habitat invasions by alien plants: a quantitative comparison among Mediterranean, subcontinental and oceanic regions of Europe. Journal of Applied Ecology 45:448-458.

Chytrý, M., and Z. Otýpková. 2003. Plot sizes used for phytosociological sampling of European vegetation. Journal of Vegetation Science 14:563-570.

Chytrý, M., P. Pyšek, L. Tichý, I. Knollová, and J. Danihelka. 2005. Invasions by alien plants in the Czech Republic: a quantitative assessment across habitats. Preslia 77:339-354.

Chytrý, M., and M. Rafajová. 2003. Czech National Phytosociological Database: basic statistics of the available vegetation-plot data. Preslia 75:1-15.

Colwell, R. K., C. X. Mao, and J. Chang. 2004. Interpolating, extrapolating, and comparing incidence-based species accumulation curves. Ecology 85:2717-2727.

Crawley, M. J. 1987. What makes a community invasible? Pages 429-453 in A. J. Gray, M. J. Crawley, and P. J. Edwards, editors. Colonization: succession and stability. Blackwell Scientific, Oxford, UK.

Darlington, P. J. 1965. Biogeography of the southern end of the world. Harvard University Press, Cambridge, Massachusetts, USA.

Darwin, C. 1859. On the origins of species by means of natural selection. Murray, London, UK.

Davis, M. A., J. P. Grime, and K. Thompson. 2000. Fluctuating resources in plant communities: a general theory of invasibility. Journal of Ecology 88:528-534.

Dengler, J., J. Oldeland, F. Jansen, M. Chytrý, J. Ewald, M. Finckh, M. Glöckler, G. Lopez-Gonzales, R. K. Peet, and J. H. J. Schaminée. 2012. Vegetation databases for the 21st century. Biodiversity \& Ecology 4:233-241.

di Castri, F. 1989. History of biological invasions with special emphasis on the Old World. Pages 1-30 in J. A. Drake, H. A. Mooney, F. di Castri, R. H. Groves, F. J. Kruger, M. Rejmanek, and M. Williamson, editors. Biological invasions: a global perspective. John Wiley, Chichester, UK.

Fridley, J. D. 2008. Of Asian forests and European fields: eastern U.S. plant invasion in a global context. PLoS ONE 3: e3630.

Fridley, J. D. and D. F. Sax. 2014. The imbalance of nature: revisiting a Darwinian framework for invasion biology. Global Ecology and Biogeography 23:1157-1166.

Hejda, M., M. Chytrý, J. Pergl, and P. Pyšek. 2015. Nativerange habitats of invasive plants: are they similar to invadedrange habitats and do they differ according to the geographical direction of invasion? Diversity and Distributions 21: $312-321$.

Kalusová, V., M. Chytrý, J. T. Kartesz, M. Nishino, and P. Pyšek. 2013. Where do they come from and where do they go? European natural habitats as donors of invasive alien plants globally. Diversity and Distributions 19:199-214.

Kalusová, V., M. Chytrý R. K. Peet, and T. R. Wentworth. 2014. Alien species pool influences the level of habitat invasion in intercontinental exchange of alien plants. Global Ecology and Biogeography 23:1366-1375.

Kelly, A. B., C. J. Small, and G. D. Dreyer. 2009. Vegetation classification and invasive species distribution in natural areas of southern New England. Journal of the Torrey Botanical Society 136:500-519.

Kowarik, I. 1995. Time lags in biological invasions with regard to the success and failure of alien species. Pages 15-38 in P. 
Pyšek, K. Prach, M. Rejmánek, and M. Wade, editors. Plant invasions: general aspects and special problems. SPB Academic Publishers, Amsterdam, Netherlands.

Kubát, K., L. Hrouda, J. Chrtek, Jr., Z. Kaplan, J. Kirschner, and J. Stěpánek. 2002. Key to the flora of the Czech Republic. Academia, Praha, Czech Republic. [In Czech.]

Legendre, P., and L. Legendre. 2012. Numerical ecology. Third edition. Elsevier, Amsterdam, Netherlands.

Lonsdale, W. M. 1999. Global patterns of plant invasions and the concept of invasibility. Ecology 80:1522-1536.

Maskell, L. C., J. M. Bullock, S. M. Smart, K. Thompson, and P. E. Hulme. 2006a. The distribution and habitat associations of non-native plant species in urban riparian habitats. Journal of Vegetation Science 17:499-508.

Maskell, L. C., L. G. Firbank, K. Thompson, J. M. Bullock, and S. M. Smart. 2006b. Interactions between non-native plant species and the floristic composition of common habitats. Journal of Ecology 94:1052-1060.

Medvecká, J., I. Jarolímek, D. Senko, and M. Svitok. 2014. Fifty years of plant invasion dynamics in Slovakia along 2,500 m altitudinal gradient. Biological Invasions 16:16271638.

Peet, R. K., T. M. Lee, F. Boyle, T. R. Wentworth, M. P. Schafale, and A. S. Weakley. 2012. Vegetation-plot database of the Carolina Vegetation Survey. Biodiversity and Ecology $4: 243-253$.

Peet, R. K., T. R. Wentworth, and P. S. White. 1998. A flexible, multipurpose method for recording vegetation composition and structure. Castanea 63:262-274.

Pimentel, D., L. Lach, R. Zuniga, and D. Morrison. 2000. Environmental and economic costs associated with nonindigenous species in the United States. BioScience 50:53-65.

Planty-Tabacchi, A. M., E. Tabacchi, and M. J. S. Bonillo. 2001. Invasions of river corridors by exotic plant species: patterns and causes. Pages 221-234 in G. Brundu, J. Brock, I. Camarda, L. Child, and M. Wade, editors. Plant invasions: species ecology and ecosystem management. Backhuys Publishers, Leiden, Netherlands.

Planty-Tabacchi, A., E. Tabacchi, R. Naiman, C. DeFerari, and H. Décamps. 1996. Invasibility of species-rich communities in riparian zones. Conservation Biology 10:598-607.

Pyšek, P., and M. Chytrý. 2014. Habitat invasion research: where vegetation science and invasion ecology meet. Journal of Vegetation Science 25:1181-1187.

Pyšek, P., M. Chytrý, and V. Jarošík. 2010. Habitats and land use as determinants of plant invasions in the temperate zone of Europe. Pages 66-79 in C. Perrings, H. Mooney, and M. Williamson, editors. Bioinvasions and globalization: ecology, economics, management and policy. Oxford University Press, Oxford, UK.

Pyšek, P., et al. 2012. Catalogue of alien plants of the Czech Republic (Second edition): checklist update, taxonomic diversity and invasion patterns. Preslia 84:155-255.

Pyšek, P., D. M. Richardson, J. Pergl, V. Jarošík, Z. Sixtová, and E. Weber. 2008. Geographical and taxonomic biases in invasion ecology. Trends in Ecology \& Evolution 23:237244.

Pyšek, P., J. Sádlo, and B. Mandák. 2002. Catalogue of alien plants of the Czech Republic. Preslia 74:97-186.

Rejmánek, M., D. M. Richardson, and P. Pyšek. 2005. Plant invasions and invasibility of plant communities. Pages 332355 in E. van der Maarel, editor. Vegetation ecology. Blackwell Science, Oxford, UK.

Richardson, D. M., P. M. Holmes, K. J. Esler, S. M. Galatowitsch, J. C. Stromberg, S. P. Kirkman, P. Pyšek, and R. J. Hobbs. 2007. Riparian vegetation: degradation, alien plant invasions and restoration prospects. Diversity and Distributions 13:126-139.

Richardson, D. M., and M. Rejmánek. 2011. Trees and shrubs as invasive alien species - a global review. Diversity and Distributions 17:788-809.

Sádlo, J., M. Chytrý, and P. Pyšek. 2007. Regional species pools of vascular plants in habitats of the Czech Republic. Preslia 79:303-321.

Seastedt, T. R., and P. Pyšek. 2011. Mechanisms of plant invasions of North American and European grasslands. Annual Review of Ecology, Evolution, and Systematics 42: 133-153.

Sîrbu, C., A. Oprea, C. Samuil, and C. Tănase. 2012. Neophyte invasion in Moldavia (eastern Romania) in different habitat types. Folia Geobotanica 47:215-229.

Statsoft. 2010. STATISTICA, version 9.1. Data analysis software system. Statsoft, Tulsa, Oklahoma, USA.

Stohlgren, T. J., D. Barnett, C. Flather, J. Kartesz, and B. Peterjohn. 2005. Plant species invasions along the latitudinal gradient in the United States. Ecology 86:2298-2309.

Stohlgren, T. J., D. Binkley, G. W. Chong, M. A. Kalkhan, L. D. Schell, K. A. Bull, Y. Otsuki, G. Newman, M. Bashkin, and Y. Son. 1999. Exotic plant species invade hot spots of native plant diversity. Ecological Monographs 69:25-46.

Thuiller, W., D. M. Richardson, P. Pyšek, G. Migdley, G. Hughes, and M. Rouget. 2005. Niche-based modelling as a tool for predicting the risk of alien plant invasion at a global scale. Global Change Biology 11:2234-2250.

Tichý, L. 2002. JUICE, software for vegetation classification. Journal of Vegetation Science 13:451-453.

Vilà, M., J. L. Espinar, M. Hejda, P. E. Hulme, V. Jarošík, J. L. Maron, J. Pergl, U. Schaffner, Y. Sun, and P. Pyšek. 2011. Ecological impacts of invasive alien plant species: a metaanalysis of their effects on species, communities and ecosystems. Ecology Letters 14:702-708.

Vilà, M., J. Pino, and X. Font. 2007. Regional assessment of plant invasions across different habitat types. Journal of Vegetation Science 18:35-42.

Wiser, S. K., J. M. Hurst, E. F. Wright, and R. B. Allen. 2011. New Zealand's forest and shrubland communities: a quantitative classification based on a nationally representative plot network. Applied Vegetation Science 14:506-523.

\section{Supplemental Material}

\section{Ecological Archives}

Appendices A-C are available online: http://dx.doi.org/10.1890/15-0021.1.sm 